\title{
Synthesis and Characterization of Thiophene-Based Copolymers Containing Urethane and Alkyl Functional Side Chains for Hybrid Bulk Heterojunction Photovoltaic Cell Applications
}

\author{
Min Joung Im, Chul Hyun Kim, Myungkwan Song, Jin Su Park, Jae Wook Lee ${ }^{\dagger}$ Yeong-Soon Gal, ${ }^{\dagger}$ \\ Jun Hee Lee, ${ }^{\S}$ and Sung-Ho Jin*

\begin{abstract}
Department of Chemistry Education and Interdisciplinary Program of Advanced Information and Display Materials, Pusan National University, Busan 609-735, Korea. *E-mail: shjin@pusan.ac.kr

${ }^{\dagger}$ Department of Chemistry, Dong-A University, Busan 604-714, Korea

${ }^{\ddagger}$ Polymer Chemistry Lab., Kyungil University, Hayang 712-701, Korea

${ }^{\S}$ Department of Advanced Materials Engineering, Dong-A University, Busan 604-714, Korea

Received June 22, 2010, Accepted December 6, 2010
\end{abstract}

\begin{abstract}
The following noble series of statistical copolymers, poly[(2-(3-thienyl)ethanol $n$-butoxycarbonylmethylurethane)co-3-hexylthiophene] (PURET-co-P3HT), were synthesized by the chemical dehydrogenation method using anhydrous $\mathrm{FeCl}_{3}$. The structure and electro-optical properties of these copolymers were characterized using ${ }^{1} \mathrm{H}-\mathrm{NMR}, \mathrm{UV}$-visible spectroscopy, elemental analysis, GPC, DSC, TGA, photoluminescence (PL), and cyclic voltammetry (CV). The statistical copolymers, PURET-co-P3HT (1:0, 2:1, 1:1, 1:2, 1:3), were soluble in common organic solvents and easily spin coated onto indium-tin oxide (ITO) coated glass substrates. Hybrid bulk heterojunction photovoltaic cells with an ITO/G-PEDOT/PURET-co-P3HT:PCBM:Ag nanowires/TiO $/ \mathrm{Al}$ configuration were fabricated, and the photovoltaic cells using PURET-co-P3HT (1:2) showed the best photovoltaic performance compared with those using PURET-co-P3HT (1:0, 2:1, 1:1, 1:3). The optimal hybrid bulk heterojunction photovoltaic cell exhibits a power conversion efficiency (PCE) of $1.58 \%\left(\mathrm{~V}_{\mathrm{oc}}=0.82 \mathrm{~V}, \mathrm{~J}_{\mathrm{sc}}=5.58, \mathrm{FF}=0.35\right)$ with PURET-co-P3HT (1:2) measured by using an $\mathrm{AM} 1.5 \mathrm{G}$ irradiation $\left(100 \mathrm{~mW} / \mathrm{cm}^{2}\right)$ on an Oriel Xenon solar simulator (Oriel $300 \mathrm{~W}$ ).
\end{abstract}

Key Words: PURET-co-P3HT, Hybrid bulk heterojunction, Ag Nanowires, $\mathrm{TiO}_{\mathrm{x}}$

\section{Introduction}

$\pi$-Conjugated polymers are expected to have great potential in future electronic-photonic conversion systems, such as polymer light-emitting diodes (PLEDs), ${ }^{1}$ organic photovoltaic cells $(\mathrm{OPVs})^{2}$ and organic thin film transistors (OTFTs). ${ }^{3}$ The design of electronic materials on the molecular level has the potential for modulation of electro-optical properties such as covering the visible to near infrared spectrum and the harvesting of the entire solar spectrum by photovoltaic cells is an active research area. Organic photovoltaic cells offer great technological potential as a renewable and alternative source for electrical energy. They can be flexible and be made from solution processing methods such as spin coating, doctor blade, screen, or ink-jet printing methods. ${ }^{4}$ Among the different concepts that have been proposed in OPVs, the bulk heterojunction approach is attractive and has provided significant progress in improving the power conversion efficiency (PCE) of these photovoltaic cells in recent years. One of the possible ways of improving the PCE of photovoltaic cells is the implementation of new materials absorbing the part of the solar spectrum. Therefore, it is important to design and synthesize new functional polymers that improve the overlap of the polymer absorption spectrum with the standard solar spectrum under AM 1.5 global. ${ }^{5-6}$ Among the $\pi$-conjugated polymers, polythiophene derivatives, especially regioregular poly(3-hexylthiophene) (P3HT) present special opportunities because of the higher level of crystallinity, possibilities in structural modification, the superior electronic and mechanical properties and are stable toward oxygen and humidity at an ambient temperature. ${ }^{7}$ For bulk heterojunction OPVs, blend of $\mathrm{P} 3 \mathrm{HT}$ or low-bandgap polymers with fullerene derivatives exhibited a high PCE to date. ${ }^{8}$ One particular or low-bandgap polymer, PCDTBT, has revealed a PCE up to $6 \%$. ${ }^{9}$ One successful approach for synthesizing functional polymers is to introduce the different comonomers in repeating units along a polymer backbone via copolymerization method. The copolymerization process has been used widely in the preparation of functional polymers with the aim of achieving a high molecular weight, easy processing for fabrication of devices, and easy tuning of the electro-optical properties, which arises from synergistic effects between the two monomers. ${ }^{10-11}$ Recently many research groups reported the synthesis of polythiophene derivatives containing butoxycarbonylmethyl urethane side group, poly[2-(3-thienyl) ethanol $n$-butoxy carbonylmethyl methane] (PURET) to solubilize rigid polymers in common organic solvents. ${ }^{12-13}$ For ideal performance, OPVs should fulfill several other requirements, including efficient absorption of sunlight, excellent charge carrier generation, transport and collection. To attain these properties, hybrid bulk heterojunction photovoltaic cells have been designed that combine blends of $\pi$-conjugated polymers with $n$-type inorganic nanocrystals, in order to take advantage of high electron mobility, excellent chemical and physical stability seen with inorganic semiconductors. ${ }^{14}$ Several polymer-inorganic hybrid photovoltaic cells that employ $\mathrm{PbS},{ }^{15}$ $\mathrm{CdS},{ }^{16} \mathrm{ZnO},{ }^{17} \mathrm{CdSe},{ }^{18} \mathrm{CdTe}^{19}$ tetrapods ${ }^{20}$ and $\mathrm{TiO}_{2}$ nanoparticles $^{21}$ have been reported. Metal nanoparticles, such as those of 
silver and gold, possess localized surface plasmon that exhibit resonance light absorption in the visible region. Ag nanowires with well-defined dimensions represent a particularly interesting class of nanostructures because bulk Ag exhibits the highest electrical and thermal conductivity among all metals.

The PURET group showed electro-optical properties such as strong luminescence and reversible oxidation processes. The P3HT exhibited high PCE due to the excellent electron donor and transport properties in OPVs. Therefore, in this paper, we report the synthesis and characterization of a series of $\pi$-conjugated statistical copolymers (PURET-co-P3HT) derived from PURET and P3HT and used as active materials for the fabrication of hybrid bulk heterojunction photovoltaic cells from synergistic effects between PURET, P3HT and Ag nanowires. The preparation of these copolymers along with an analysis of their thermal, optical, electrochemical properties as well as photovoltaic properties is described below.

\section{Experimental Section}

Materials. All the reagents were purchased from Sigma-Aldrich and used without further purification. The solvents were purified using standard procedures and were handled in a moisture free atmosphere. Ag nanowires were synthesized by reducing $\mathrm{AgNO}_{3}$ with anhydrous ethylene glycol in the presence of $\mathrm{Pt}$ (or Ag) seeds and poly(vinylpyrrolidone). ${ }^{22}$ Unless otherwise noted, these solvents were used without further purification.

Characterization. The ${ }^{1} \mathrm{H}-\mathrm{NMR}$ spectra were recorded on a Bruker AM-300 spectrometer. The UV-visible spectra were recorded with a Jasco V-570 spectrophotometer with a baseline correction. The emission spectra for the dilute solutions were determined using a Hitachi F-4500 fluorescence spectrophotometer. The solid state emission measurements were carried out by supporting each film on a quartz substrate, which was mounted to receive front-face excitation at an angle $<45^{\circ}$. Each polymer film was excited with several portions of the visible spectrum using a xenon lamp. The molecular weight and polydispersity of the polymer were determined by gel permeation chromatography (GPC) using a PL gel $5 \mu \mathrm{m}$ MIXED-C column on an Agilent 1100 series liquid chromatography system with THF as the eluent and calibration with polystyrene standards. Thermal analyses were carried out on a Mettler Toledo TGA/ SDTA 851, DSC 822 analyzer under an $\mathrm{N}_{2}$ atmosphere at a heating rate of $10^{\circ} \mathrm{C} / \mathrm{min}$. Cyclic voltammetry $(\mathrm{CV})$ was carried out in a $0.1 \mathrm{M}$ solution of tetrabutylammonium tetrafluoroborate $\left(\mathrm{Bu}_{4} \mathrm{NBF}_{4}\right)$ in anhydrous acetonitrile using a Bioanalytical Systems CV-50W voltammetric analyzer at a potential scan rate of $50-100 \mathrm{mV} / \mathrm{s}$. Each polymer film was coated onto a Pt disc electrode $\left(0.2 \mathrm{~cm}^{2}\right)$ by dipping the electrode into the polymer solution $(10 \mathrm{mg} / \mathrm{mL})$. A platinum wire was used as the counter electrode, and a $\mathrm{Ag} / \mathrm{AgNO}_{3}$ electrode was used as the reference electrode. All electrochemical experiments were performed at room temperature in a glove box in an Ar atmosphere.

Synthesis of Poly((2-(3-thienyl)ethanol $\boldsymbol{n}$-butoxycarbonylmethylurethane)-co-3-hexylthiophene) (PURET-co-P3HT) (1:1 mol \%). The 2-(3-thienyl)ethanol $n$-butoxycarbonylmethylurethane (URET) and 3-hexylthiophene were copolymerized by the chemical dehydrogenation method using anhydrous $\mathrm{FeCl}_{3}$.
A solution of URET $(0.42 \mathrm{~g}, 1.5 \mathrm{mmol})$ and 3-hexylthiophene $(0.26 \mathrm{~mL}, 1.5 \mathrm{mmol})$ in $5 \mathrm{~mL}$ of chloroform was polymerized using $\mathrm{FeCl}_{3}(1 \mathrm{~g}, 6 \mathrm{mmol})$ at $30{ }^{\circ} \mathrm{C}$ for $12 \mathrm{~h}$ under an $\mathrm{N}_{2}$ atmosphere. After stirring the mixture, the polymerization solution was poured into $100 \mathrm{~mL}$ of methanol and the crude polymer was successively Soxhlet extracted with methanol and acetone for 3 days to remove the unreacted monomers and oligomers. The PURET-co-P3HT was finally washed with aqueous ammonia solution followed by methanol to remove the trace amounts of iron impurities. The precipitated product was filtered and then dried in vacuo to give the dark brown solid product. Other copolymers were prepared by analogous procedures with various feed ratios.

PURET-co-P3HT(1:1 mol \%): ${ }^{1} \mathrm{H}-\mathrm{NMR}\left(300 \mathrm{MHz}, \mathrm{CDCl}_{3}\right.$,

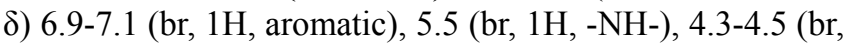
$2 \mathrm{H},-\mathrm{CH}_{2}-$ ), 4.1-4.2 (br, 2H, $-\mathrm{CH}_{2}-$ ), 3.8-4.0 (br, 2H, $-\mathrm{CH}_{2-}$ ), 3.1-3.2 (br, $2 \mathrm{H},-\mathrm{CH}_{2}-$ ), 2.7-2.9 (br, $1.7 \mathrm{H},-\mathrm{CH}_{2-}^{-}$, head-to-tail coupling), 2.5-2.9 (br, 2H, - $\mathrm{CH}_{2}$ ), 1.5-1.7 (br, 4H, - $\mathrm{CH}_{2}$ aliphatic protons), 1.2-1.4 (br, $8 \mathrm{H},-\mathrm{CH}_{2}$-aliphatic protons), 0.8-1.0 (br, $6 \mathrm{H},-\mathrm{CH}_{3}$-aliphatic protons Anal. Calcd for $\left(\mathrm{C}_{25} \mathrm{H}_{37} \mathrm{NO}_{4} \mathrm{~S}_{2}\right)_{\mathrm{n}}$ : C, 63.13; H, 6.99; N, 2.94; S, 13.48. Found: C, 63.13; H, 7.11; N, 2.89; S, 12.50 .

The homopolymer (PURET) was synthesized using a slight modification of the method reported in the literature. ${ }^{23}$

Poly[2-(3-thienyl)ethanol $\boldsymbol{n}$-butoxycarbonylmethylurethane] (PURET): ${ }^{1} \mathrm{H}-\mathrm{NMR}\left(300 \mathrm{MHz}, \mathrm{CDCl}_{3}, \delta\right)$ 6.9-7.1 (br, $1 \mathrm{H}$, aromatic), 5.5 (br, 1H, -NH-), 4.3-4.5 (br, 2H, - $\mathrm{CH}_{2}-$ ), 4.1-4.2 (br, $2 \mathrm{H},-\mathrm{CH}_{2}-$ ), 3.8-4.0 (br, $2 \mathrm{H},-\mathrm{CH}_{2}-$ ), 3.1-3.2 (br, $2 \mathrm{H},-\mathrm{CH}_{2-}$ ), 1.5-1.7 (br, $2 \mathrm{H},-\mathrm{CH}_{2}$ aliphatic protons), 1.2-1.4 (br, $2 \mathrm{H},-\mathrm{CH}_{2}-$ aliphatic protons), $0.8-1.0$ (br,2H, $-\mathrm{CH}_{3}$ - aliphatic protons). Anal. Calcd for $\left(\mathrm{C}_{15} \mathrm{H}_{23} \mathrm{NO}_{4} \mathrm{~S}\right)_{\mathrm{n}}$ : C, 56.93; H, 5.80; N, 4.74; S, 10.86. Found: C, 53.68; H, 5.79; N, 4.64; S, 12.05.

PURET-co-P3HT (2:1 mol \%): ${ }^{1} \mathrm{H}-\mathrm{NMR}\left(300 \mathrm{MHz}, \mathrm{CDCl}_{3}\right.$,

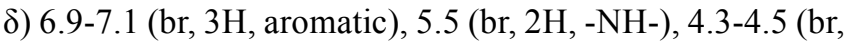
$4 \mathrm{H},-\mathrm{CH}_{2}-$ ), 4.1-4.2 (br, 4H, $-\mathrm{CH}_{2}-$ ), 3.8-4.0 (br, 4H, $-\mathrm{CH}_{2-}$ ), 3.1-3.2 (br, $4 \mathrm{H},-\mathrm{CH}_{2}-$ ), 2.5-2.9 (br, $2 \mathrm{H},-\mathrm{CH}_{2}$ ), 1.5-1.7 (br, $6 \mathrm{H}$, - $\mathrm{CH}_{2}$ aliphatic protons), 1.2-1.4 (br, $10 \mathrm{H},-\mathrm{CH}_{2}$-aliphatic protons), 0.8-1.0 (br, 9H, - $\mathrm{CH}_{3}$ - aliphatic protons). Anal. Calcd for $\left(\mathrm{C}_{35} \mathrm{H}_{54} \mathrm{~N}_{2} \mathrm{O}_{8} \mathrm{~S}_{3}\right)_{\mathrm{n}}$ : C, 59.65; H, 6.49; N, 3.76; S, 12.91. Found: C, 59.46; H, 6.88; N, 3.16; S, 14.58 .

PURET-co-P3HT(1:2 mol \%): ${ }^{1} \mathrm{H}-\mathrm{NMR}\left(300 \mathrm{MHz}, \mathrm{CDCl}_{3}\right.$,

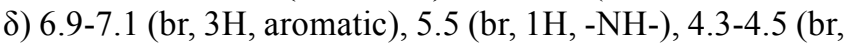
2H, $-\mathrm{CH}_{2}-$ ), 4.1-4.2 (br, 2H, - $\mathrm{CH}_{2}-$ ), 3.8-4.0 (br, $2 \mathrm{H},-\mathrm{CH}_{2}-$ ), 3.1-3.2 (br, $2 \mathrm{H},-\mathrm{CH}_{2}-$ ), 2.5-2.9 (br, $4 \mathrm{H},-\mathrm{CH}_{2}$ ), 1.5-1.7 (br, $6 \mathrm{H}$, $-\mathrm{CH}_{2}$ aliphatic protons), 1.2-1.4 (br, $14 \mathrm{H},-\mathrm{CH}_{2}$-aliphatic protons), 0.8-1.0 (br, $9 \mathrm{H},-\mathrm{CH}_{3}$ aliphatic protons). Anal. Calcd for $\left(\mathrm{C}_{35} \mathrm{H}_{51} \mathrm{NO}_{4} \mathrm{~S}_{3}\right)_{\mathrm{n}}: \mathrm{C}, 65.48 ; \mathrm{H}, 7.38 ; \mathrm{N}, 2.18 ; \mathrm{S}, 14.98$. Found: C, 66.50; H, 7.81; N, 1.00; S, 18.20.

PURET-co-P3HT(1:3 mol \%): ${ }^{1} \mathrm{H}-\mathrm{NMR}\left(300 \mathrm{MHz}, \mathrm{CDCl}_{3}\right.$,

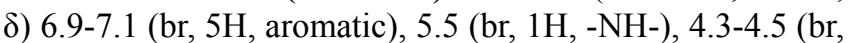
$2 \mathrm{H},-\mathrm{CH}_{2}-$ ), 4.1-4.2 (br, 2H, $-\mathrm{CH}_{2}-$ ), 3.8-4.0 (br, $2 \mathrm{H},-\mathrm{CH}_{2-}$ ), 3.1-3.2 (br, $2 \mathrm{H},-\mathrm{CH}_{2}-$ ), 2.5-2.9 (br, 7.5H, $-\mathrm{CH}_{2}$ ), 1.5-1.7 (br, $11 \mathrm{H},-\mathrm{CH}_{2}$ aliphatic protons), 1.2-1.4 (br, $26 \mathrm{H},-\mathrm{CH}_{2}$-aliphatic protons), 0.8-1.0 (br, $15 \mathrm{H},-\mathrm{CH}_{3}$-aliphatic protons). Anal. Calcd for $\left(\mathrm{C}_{65} \mathrm{H}_{93} \mathrm{NO}_{4} \mathrm{~S}_{6}\right)_{\mathrm{n}}: \mathrm{C}, 68.43 ; \mathrm{H}, 7.86 ; \mathrm{N}, 1.23 ; \mathrm{S}, 16.86$. Found: C, 68.12; H, 8.18; N, 0.60; S, 19.55 .

Fabrication of the Hybrid Bulk Heterojunction Photovoltaic Cells. The hybrid bulk heterojunction photovoltaic cells were 
fabricated by spin-coating a $40 \mathrm{~nm}$ thick layer of G-PEDOT: PSS, which was prepared by adding $6 \mathrm{wt} \%$ glycerol to PEDOT: PSS (Baytron PH) on a ultrasonically cleaned $100 \mathrm{~nm}$ thick ITO coated patterned glass substrate. The coated substrates were then baked on a hot plate at $120{ }^{\circ} \mathrm{C}$ for $10 \mathrm{~min}$. Specifically, the hybrid bulk heterojunction photovoltaic cells were fabricated using a 1:1 weight ratio of $o$-dichlorobenzene and chloroform solvent mixture containing a 1:6 weight ratio of PURET-co$\mathrm{P} 3 \mathrm{HT}$ and $\mathrm{PCBM}$ in the presence of $8 \mathrm{wt} \% \mathrm{Ag}$ nanowires. The hybrid bulk heterojunction photovoltaic cell structure was completed by depositing $\mathrm{Al}(100 \mathrm{~nm})$ as the top electrode under a vacuum $<3 \times 10^{-6}$ Torr in a vacuum evaporator attached to a glove box on the polymer active layer. The overlap of the two electrodes defined the active area of the photovoltaic cell, which was $4 \mathrm{~mm}^{2}$. The performance of the hybrid bulk heterojunction photovoltaic cells was measured using a calibrated AM 1.5 G solar simulator (Oriel $300 \mathrm{~W}$ ) at a $100 \mathrm{~mW} / \mathrm{cm}^{2}$ light intensity adjusted with a standard PV reference cell $(3 \mathrm{~cm} \times 3 \mathrm{~cm}$ monocrystalline silicon solar cell, calibrated at NREL, Colorado, USA). The electric data was recorded using a Keithley 236 source-measure unit. All fabrication steps and characterization measurements were carried out in an ambient environment with out a protective atmosphere. The data was verified by fabricating each device at least 5 times.

\section{Results and Discussion}

Synthesis and Characterization. Scheme 1 outlines the synthetic routes of the monomer and the copolymers. 2-(3-Thienyl)ethanol $n$-butoxycarbonylmethylurethane (URET) and poly(2-(3-thienyl)ethanol $n$-butoxycarbonylmethylurethane) (PURET) were synthesized using published procedures. ${ }^{23}$ The URET monomer containing urethane side chain and 3-hexylthiophene were copolymerized using the chemical dehydrogenation method using anhydrous $\mathrm{FeCl}_{3}$ and characterized their photovoltaic properties of hybrid bulk heterojunction photo-

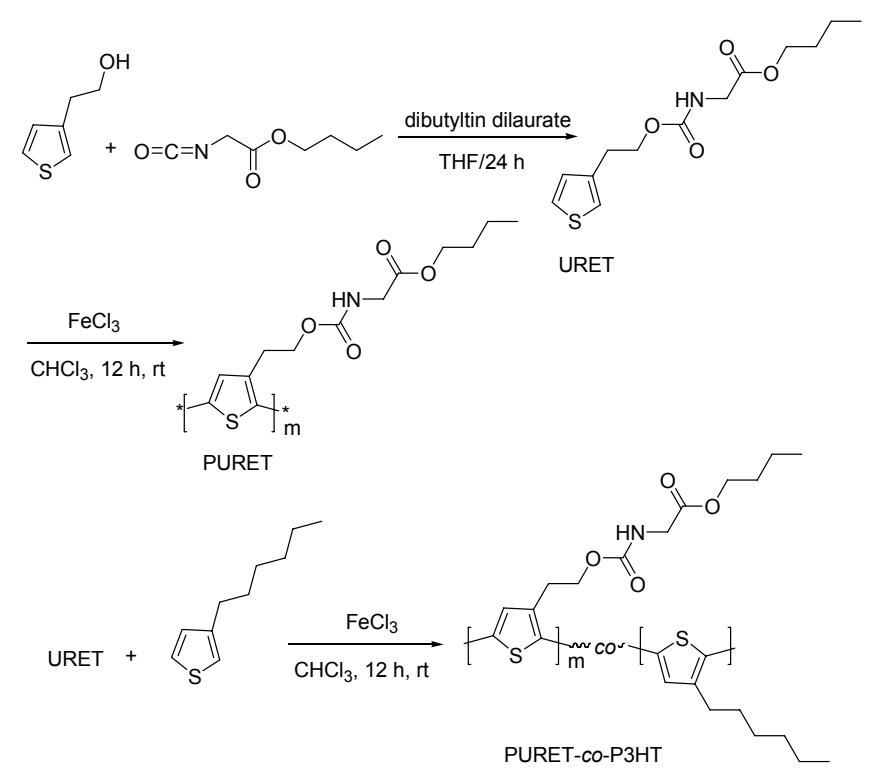

Scheme 1. Synthetic Process of Monomer and Polymers voltaic cells as an electron donor. The monomer feed ratios were adjusted in order to examine the effects of various copolymer compositions on the UV-visible, PL and photovoltaic properties. The comonomer feed ratios of 2-(3-thienyl)ethanol $n$-butoxycarbonylmethylurethane to 3-hexylthiophene were 1:0, 2:1, 1:1, $1: 2$, and $1: 5$ mole $\%$, respectively. The copolymer compositions were calculated by comparing the peak area at $4.1-4.2$ ppm of the methylene proton next to oxygen in urethane side group and at 2.7 - $2.9 \mathrm{ppm}$ of the methylene proton on 3-hexylthiophene groups as side chains. The actual composition ratio of PURET-co-P3HT (1:0, 2:1, 1:1, 1:2) is in good agreement with the feed ratios of the two monomers within experimental error. However, PURET-co-P3HT (1:5) did not agree with the feeding ratio with less 3-hexylthiophene monomer ratio than the feed ratio. The actual composition ratio of the PURET-coP3HT (1:5) was PURET-co-P3HT (1:3) and the corresponding copolymers were named as PURET-co-P3HT (1:0), PURETco-P3HT (2:1), PURET-co-P3HT (1:1), PURET-co-P3HT (1:2), and PURET-co-P3HT (1:3), respectively. The weight-average molecular weights $\left(\mathrm{M}_{\mathrm{w}}\right)$ and polydispersity of the copolymers were $(3.2-11) \times 10^{4}$ and $1.6-4.7$, respectively. Table 1 summarizes the polymerization results, molecular weights and thermal data of the copolymers. By introducing the urethane and hexyl substituents into the thiophene backbone, the resulting copolymers were completely soluble in common organic solvents such as chloroform, chlorobenzene, toluene, THF, and xylene. The chemical structures of the intermediates, monomers and the copolymers were confirmed by ${ }^{1} \mathrm{H}-\mathrm{NMR}$ spectroscopy and elemental analysis. All the peaks that were present in the monomer are also present in the copolymers, except two of the aromatic protons with resonances at 7.21 and $7.39 \mathrm{ppm}$. The presence of the proton at the $\beta$-position of the thiophene in the copolymers essentially indicates that the linear structure of the copolymers. The intensity of signals at $4.1-4.2 \mathrm{ppm}$ increased with increasing PURET segment ratio in the copolymers, while the signals at $2.7-2.9$ ppm decreased.

Thermal Properties. The thermal behavior of the copolymers was examined by DSC and TGA thermograms, as shown in Fig. 1. The urethane functionalized PURET and P3HT exhibited the glass transition temperatures $\left(\mathrm{T}_{\mathrm{g}}\right)$ at approximately $18{ }^{\circ} \mathrm{C}$ and $120^{\circ} \mathrm{C}$, respectively. As increasing the P3HT segment in

Table 1. Polymerization results, optical and thermal properties of copolymers

\begin{tabular}{cccccc}
\hline Polymer & $\begin{array}{c}\mathrm{M}_{\mathrm{w}}{ }^{a} \\
\left(\times 10^{4}\right)\end{array}$ & $\mathrm{PDI}^{a}$ & $\begin{array}{c}\mathrm{E}_{\mathrm{g}}{ }^{b} \\
(\mathrm{eV})\end{array}$ & $\begin{array}{c}\mathrm{DSC}^{c} \\
\left({ }^{\circ} \mathrm{C}\right)\end{array}$ & $\begin{array}{c}\mathrm{TGA}^{d} \\
\left({ }^{\circ} \mathrm{C}\right)\end{array}$ \\
\hline PURET-co-P3HT $(1: 0)^{e}$ & 5.2 & 1.6 & 2.15 & 18 & 261 \\
PURET-co-P3HT $(2: 1)^{e}$ & 11 & 4.7 & 2.10 & 32 & 254 \\
PURET-co-P3HT $(1: 1)^{e}$ & 5.0 & 2.1 & 2.06 & 57 & 247 \\
PURET-co-P3HT $(1: 2)^{e}$ & 3.8 & 2.8 & 1.95 & 90 & 270 \\
PURET-co-P3HT $(1: 3)^{e}$ & 3.3 & 3.3 & 1.92 & 112 & 316 \\
PURET-co-P3HT $(0: 1)^{e}$ & 3.2 & 1.9 & 1.90 & 120 & 454 \\
\hline
\end{tabular}

${ }^{a} \mathrm{M}_{\mathrm{w}}$ and PDI of the polymers were determined by GPC using polystyrene standards. ${ }^{b}$ Band gap estimated from the onset wavelength of the optical absorption. ${ }^{c}$ Determined by DSC at a heating rate of $10^{\circ} \mathrm{C} / \mathrm{min}$ under nitrogen. ${ }^{d}$ TGA was measured at temperature of $5 \%$ weight loss for the polymers. ${ }^{e}$ Composition ratio was determined from ${ }^{1} \mathrm{H}$ NMR. 
(a)

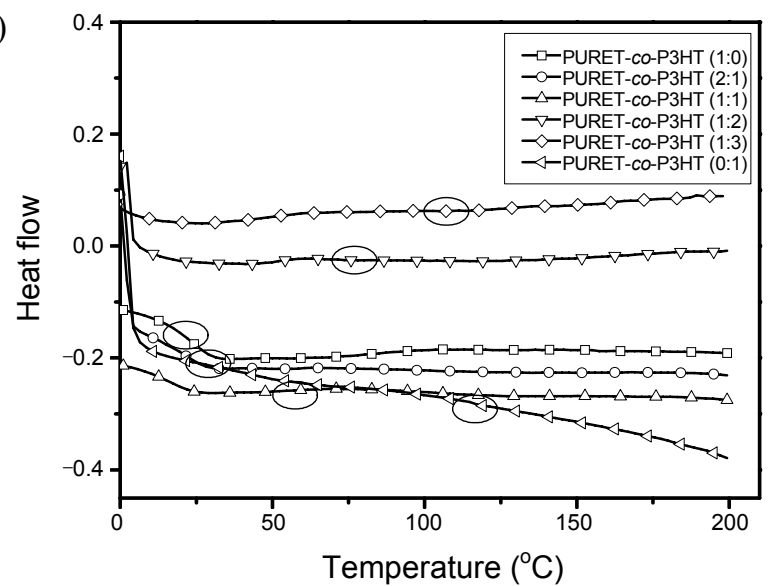

(b)

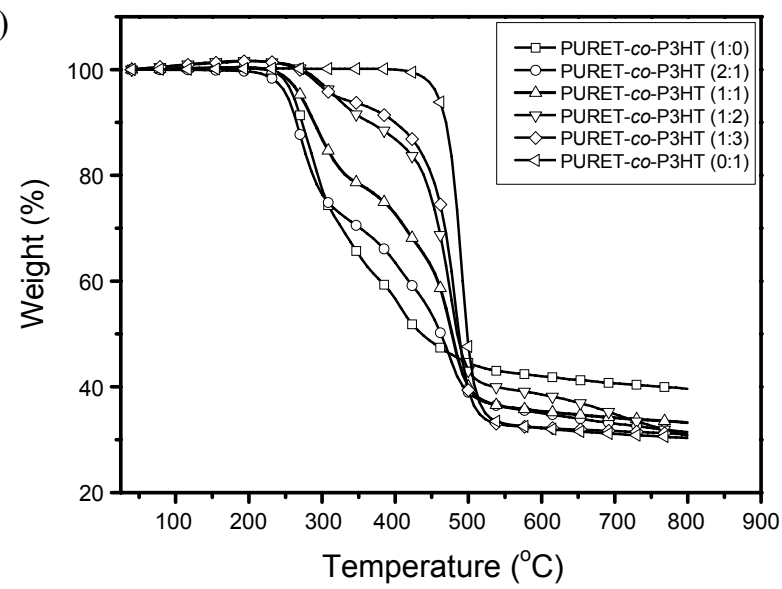

Figure 1. DSC (a) and TGA (b) thermograms of copolymers.

copolymers, the $\mathrm{T}_{\mathrm{g}}$ is increased from $32{ }^{\circ} \mathrm{C}$ to $112{ }^{\circ} \mathrm{C}$ and PURET-co-P3HT (1:3) showed a higher $\mathrm{T}_{\mathrm{g}}$ compared with the other ratios of copolymers. This is mainly due to the crystalline nature of P3HT with identification of alkyl chains. The thermograms of the copolymers showed $5 \%$ weight loss at $247^{\circ} \mathrm{C}$ to $316^{\circ} \mathrm{C}$ under a $\mathrm{N}_{2}$ atmosphere as shown in Figure $1 \mathrm{~b}$.

Optical Properties. Fig. 2a shows the normalized UV-visible absorption spectra of the copolymers in thin films states. According to the UV-visible spectrum, PURET and P3HT showed an absorption maximum at $c a .436 \mathrm{~nm}$ and $537 \mathrm{~nm}$ with a shoulder peak at $597 \mathrm{~nm}$ for P3HT in thin film state. As the P3HT content increases in copolymers the absorption maximum peak is red-shifted from $436 \mathrm{~nm}$ to $497 \mathrm{~nm}$. Such a red shift of the copolymers system could be attributed to the $\pi-\pi^{*}$ transition of the more extended $\pi$-conjugated polymer backbone. The optical band gaps $\left(\mathrm{E}_{\mathrm{g}}\right)$ of the copolymers were determined from the absorption edge and found to be in the range of $1.90-2.15$ $\mathrm{eV}$ and these results are summarized in Table 1.

PL quenching in donor-acceptor composites can evidence the photo-induced charge transfer in polymers composite films. ${ }^{24}$ Fig. $2 \mathrm{~b}$ shows the PL spectra of the PURET, P3HT, copolymers thin films and polymer:PCBM composite films, respectively. The pure PURET, P3HT, and copolymers showed a PL peak at approximately 580,658 , and $600 \mathrm{~nm}$, respectively in film state. However as shown in the inset of Figure 2b, PL spectra of polymers were quenched in the polymer:PCBM composite
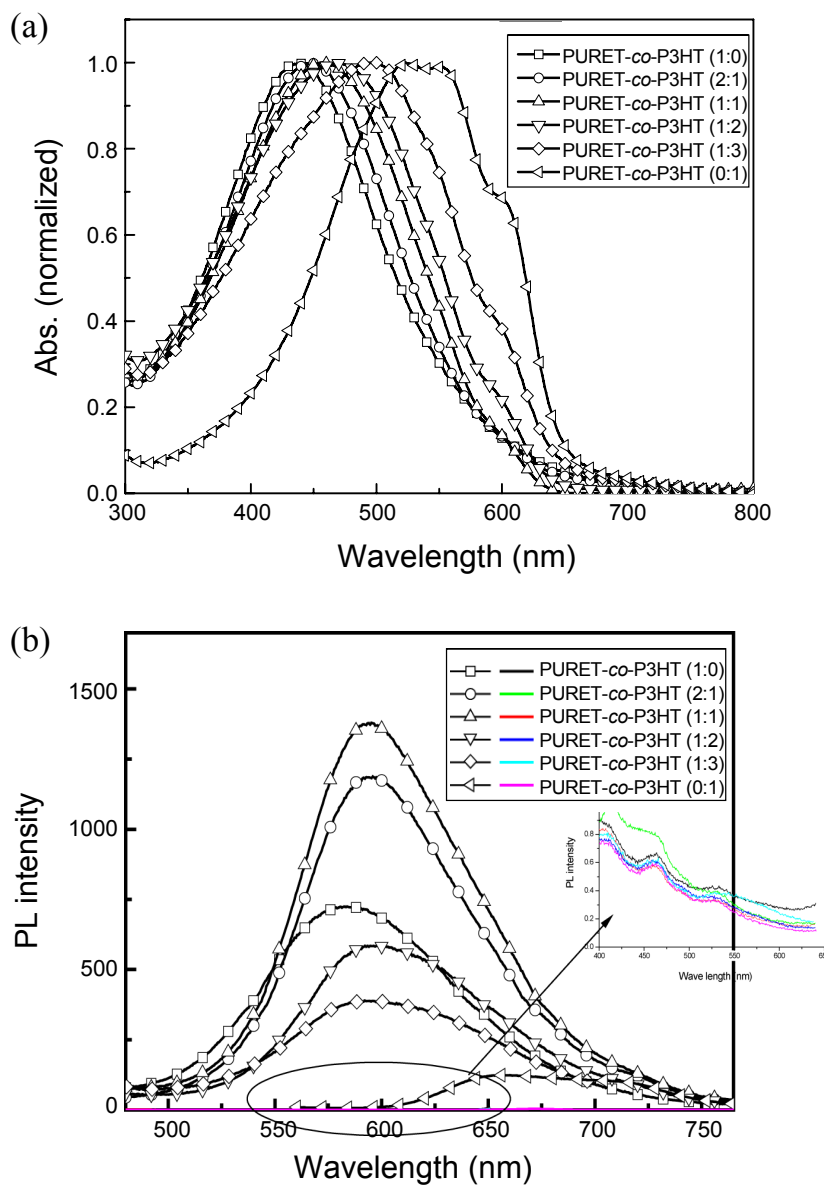

Figure 2. UV-visible absorption (a) and PL spectra (b) of the PURET, P3HT, PURET-co-P3HT and polymer:PCBM (1:6) in film state. Inset: Magnified PL spectra of the polymer:PCBM in film state.

films, as a result of efficient separation of excitons to electrons and holes.

Electrochemical Properties. To investigate the charge injection and transport properties of polymers and to determine the energies of their highest occupied (HOMO) and lowest unoccupied (LUMO) molecular orbitals, redox measurements were carried using $\mathrm{CV}$. The HOMO energies of copolymers for the standard ferrocene/ferrocenium $(4.8 \mathrm{eV})$ are found to be in the range of $5.43-5.56 \mathrm{eV}, 5.54 \mathrm{eV}$ for PURET and $5.20 \mathrm{eV}$ for P3HT, respectively. The respective LUMO energies, calculated based on the HOMO energies and the optical band gaps determined by using UV-visible absorption spectra, for polymers are found to be $3.39-3.63 \mathrm{eV}$. The energy band diagrams of PURET, P3HT, copolymers, PCBM, and $\mathrm{TiO}_{\mathrm{x}}$ are shown in Fig. 3. The energies of these electron donors are well-matched to those of PCBM as an electron acceptor. Photogeneration of charges in most of $\pi$-conjugated polymers is not very efficient since recombination of two charge carriers is always involved. However, a consideration of the high LUMO energies of PURET, P3HT, copolymers and the corresponding low HOMO energy level of PCBM leads to the prediction that charge transfer will take place at the interface of these materials.

The bulk heterojunction morphology of PURET-co-P3HT: PCBM films was investigated by AFM. AFM imaging of these 
active layer films, shown in Fig. 4, revealed relatively small scale phase separation of the polymers and PCBM components with domain sizes of less than $10 \mathrm{~nm}$. The r.m.s roughness of the PURET-co-P3HT (1:2):PCBM films film is $0.787 \mathrm{~nm}$. The surface roughness increased to $4.343 \mathrm{~nm}$ for the copolymer: PCBM films.

Photovoltaic Properties. Hybrid bulk-heterojunction photovoltaic cells were fabricated using the PURET and copolymers as the electron donor and PCBM as the electron acceptor. The hybrid bulk heterojunction photovoltaic cell structures are as follows: ITO/G-PEDOT:PSS (40 nm)/polymer:PCBM:Ag nanowires $(80 \mathrm{~nm}) / \mathrm{TiO}_{\mathrm{x}}(10 \mathrm{~nm}) / \mathrm{Al}(100 \mathrm{~nm})$ using a 1:6 ratio of donor to acceptor materials in the presence of $8 \mathrm{wt} \% \mathrm{Ag}$ nanowires at a fixed active layer thickness of $80 \mathrm{~nm}$. We also used solution processable $\mathrm{TiO}_{\mathrm{x}}{ }^{25}$ between the active layer and the metal cathode as a hole blocking and electron transporting layer. ${ }^{26}$ The energy level of $\mathrm{TiO}_{\mathrm{x}}$ matches the workfunction of $\mathrm{Al}$ well. The current density-voltage $(\mathrm{J}-\mathrm{V})$ characteristics of hybrid bulk heterojunction photovoltaic cells under AM $1.5 \mathrm{G}$ illumination, are shown in Fig. 5 and the results are summarized in Table 2. Open-circuit voltages $\left(\mathrm{V}_{\mathrm{oc}}\right)$ of bulk heterojunction photovoltaic cells are closely related to the energy difference between the HOMO level of the electron donor and the LUMO level of the electron acceptor. The device fabricated with PURET-co-P3HT(1:2) showed the highest photovoltaic performance than the devices fabricated with PURET-co-P3HT (2:1, $1: 1,1: 3)$ and PURET giving a $J_{\mathrm{sc}}$ of $5.58 \mathrm{~mA} / \mathrm{cm}^{2}$, a $\mathrm{V}_{\mathrm{oc}}$ of $0.82 \mathrm{~V}$, a FF of 0.35 , and a PCE of $1.58 \%$. The increased current density of PURET-co-P3HT (1:2) based hybrid bulk heterojunction photovoltaic cell may be due to the fine blending of the donor and acceptor components. Another factor for increasing

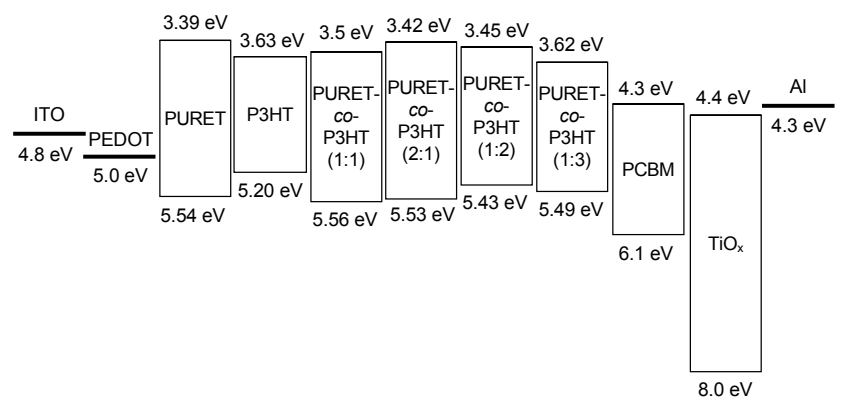

Figure 3. Energy band diagram of PURET, P3HT, copolymers, PCBM and $\mathrm{TiO}_{\mathrm{x}}$.
Table 2. Performance of hybrid bulk heterojunction photovoltaic cells using polymer:PCBM:Ag nanowires under AM 1.5 G illumination $\left(100 \mathrm{~mW} / \mathrm{cm}^{2}\right)$

\begin{tabular}{ccccc}
\hline Polymer & $\mathrm{V}_{\mathrm{oc}}(\mathrm{V})$ & $\mathrm{J}_{\mathrm{sc}}\left(\mathrm{mA} / \mathrm{cm}^{2}\right)$ & $\mathrm{FF}$ & PCE (\%) \\
\hline PURET-co-P3HT (1:0) & 0.82 & 1.57 & 0.44 & 0.56 \\
PURET-co-P3HT (2:1) & 0.76 & 4.08 & 0.37 & 1.15 \\
PURET-co-P3HT (1:1) & 0.71 & 5.20 & 0.37 & 1.36 \\
PURET-co-P3HT (1:2) & 0.82 & 5.58 & 0.35 & 1.58 \\
PURET-co-P3HT (1:3) & 0.81 & 4.73 & 0.38 & 1.47 \\
\hline
\end{tabular}

the current density is due to the UV-visible absorption spectra of the PURET-co-P3HT (1:2) film possesses the best spectral coverage of visible light, and absorption coefficient of solar light from $350 \mathrm{~nm}$ to $750 \mathrm{~nm}$ is higher than the other polymer films, which could increase the transport of charge carriers in the hybrid bulk heterojunction photovoltaic cells.

Incident photon to current conversion efficiency (IPCE) spectra of the hybrid bulk heterojunction photovoltaic cells recorded in the wavelength region between $400 \mathrm{~nm}$ and $750 \mathrm{~nm}$, are shown in Fig. 6a. An IPCE maximum of $58 \%$ at $471 \mathrm{~nm}$ was observed for a hybrid bulk heterojunction photovoltaic cells comprised of a PURET- $c$-P3HT (1:1, 1:2):PCBM/TiO ${ }_{x}$. This finding may be a result of an increase of the charge carrier mobility in the active layer and thus an increase in light absorp-

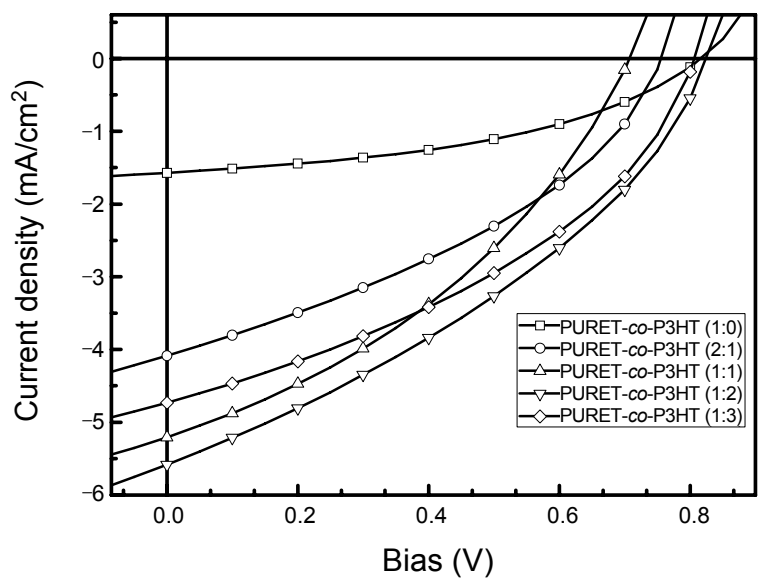

Figure 5. Current density-voltage $(\mathrm{J}-\mathrm{V})$ characteristics of the polymer: PCBM (1:6) blend of hybrid bulk heterojunction photovoltaic cells, measured at $\mathrm{AM} 1.5 \mathrm{G} 100 \mathrm{~mW} / \mathrm{cm}^{2}$ illumination.
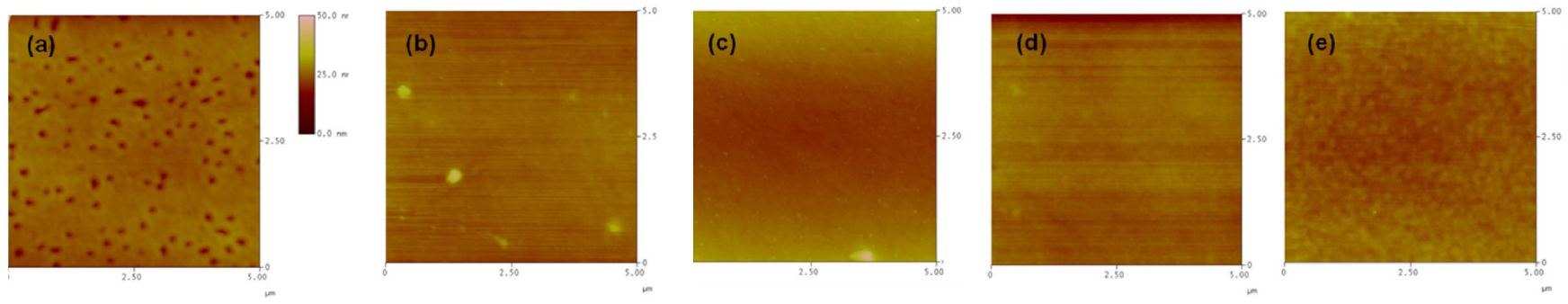

Figure 4. Tapping-mode AFM phase images of the surface of the PURET-co-P3HT:PCBM (1:6) films. (a) PURET-co-P3HT (1:0):PCBM (rms $=$ $1.833 \mathrm{~nm})(\mathrm{b})$ PURET-co-P3HT (1:1):PCBM (rms = $1.465 \mathrm{~nm})(\mathrm{c})$ PURET-co-P3HT (2:1):PCBM (rms = $4.343 \mathrm{~nm})(\mathrm{d})$ PURET-co-P3HT $(1: 2):$ PCBM $(\mathrm{rms}=0.787 \mathrm{~nm})(\mathrm{e})$ PURET-co-P3HT $(1: 3):$ PCBM $(\mathrm{rms}=1.262 \mathrm{~nm})$. 

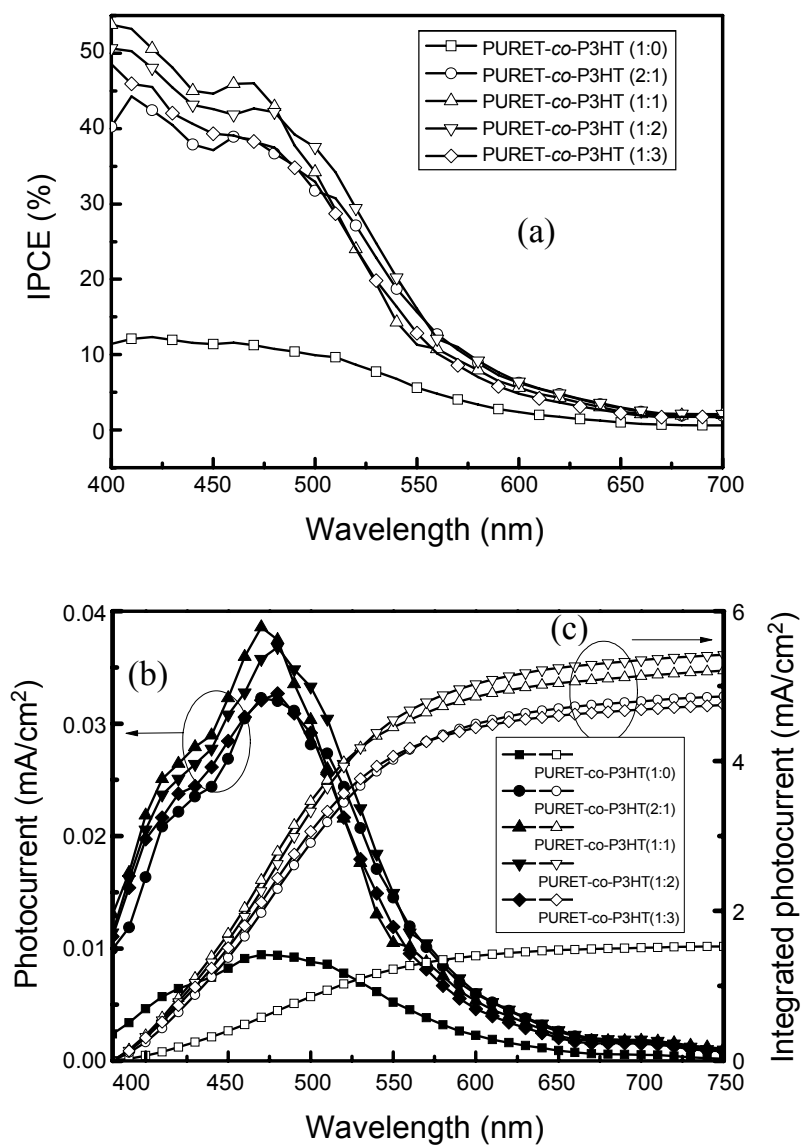

Figure 6. (a) Incident photon-to-current conversion efficiency (IPCE) curves for the hybrid bulk heterojunction photovoltaic cells (b) Photocurrents obtained using IPCE data. (c) The total solar photocurrent obtained by integrating the curves shown in plots $b$.

tion in the hybrid bulk heterojunction photovoltaic cells. Integrated photocurrent curves were obtained by integrating IPCE spectra in the wavelength region between $400 \mathrm{~nm}$ and $750 \mathrm{~nm}$ (Fig. 6b). The $\mathrm{J}_{\mathrm{sc}}$ value, determined from the overlap integral of the IPCE curve and the standard AM 1.5 G solar emission spectrum, is in excellent agreement with the measured photocurrent density. The integrated photocurrent densities of the hybrid bulk heterojunction photovoltaic cells are in the range of $1.55-5.44 \mathrm{~mA} / \mathrm{cm}^{2}$ (Fig. 6c). These values are good agreement with the measured photocurrent densities range of 1.57 $5.58 \mathrm{~mA} / \mathrm{cm}^{2}$. The error of $\mathrm{J}_{\mathrm{sc}}$ and the integrated photocurrent is $0-4 \%$, which is in the $5-10 \%$ range often seen in these values. ${ }^{27}$ Therefore, a negligible spectral mismatch exists between the solar simulator used in this study and standard AM $1.5 \mathrm{G}$ sunlight.

Studies aimed at optimizing the hybrid bulk heterojunction photovoltaic cells through thermal annealing as well as the donor to acceptor ratios for a better photovoltaic performance are currently underway.

\section{Conclusions}

A novel series of statistical copolymers, poly[(2-(3-thienyl) ethanol $n$-butoxycarbonylmethylurethane)-co-3-hexylthio- phene] (PURET-co-P3HT) were synthesized for improving photovoltaic performance of hybrid bulk heterojunction photovoltaic cells. We fabricated the hybrid bulk heterojunction photovoltaic cells with an ITO/G-PEDOT/polymer:PCBM:Ag nanowires/TiO $/ \mathrm{Al}$ using PURET and PURET-co-P3HT as the electron donor and PCBM as the electron acceptor. The copolymer feed ratio was found to have a considerable effect on the PCE. The PCE of the hybrid bulk heterojunction photovoltaic cells was found to increase with increasing P3HT content in PURET-co-P3HT and the maximum PCE of $1.58 \%$ was achieved with PURET-co-P3HT (1:2).

Acknowledgments. This work was supported by the Korea Science and Engineering Foundation (KOSEF) grant funded by the Korea government (MEST) (No. M10600000157-06J 0000-15710) and the Pioneer Research Center Program through the National Research Foundation of Korea funded by the Ministry of Education, Science and Technology (2009-0081500). This work was supported for two years by Pusan National University Grant.

\section{References}

1. Grimsdale, A. C.; Chan, K. L.; Martin, R. E.; Jokisz, P. G.; Holmes, A. B. Chem. Rev. 2009, 109, 897-1091.

2. Peet, J.; Kim, J. Y.; Coates, N. E.; Ma, W. L.; Moses, D.; Heeger, A. J.; Bazan, G. C. Nat. Mater. 2007, 6, 497-500.

3. Hamilton, R.; Smith, J.; Ogier, S.; Heeney, M.; Anthony, J. E.; McCulloch, I.; Veres, J.; Bradley, DDC.; Anthopoulos, T. D. Adv. Mater. 2009, 21, 1166-1171.

4. Shaheen, S. E.; Radspinner, R.; Peyghambarian, N.; Jabbour, G. E. Appl. Phys. Lett. 2001, 79, 2996-2998.

5. Zou, Y.; Gendron, D.; Neagu-Plesu, R.; Leclerc, M. Macromolecules 2009, 42, 6361-6365.

6. Burgi, L.; Trubiez, M.; Pfeiffer, R.; Bienewald, F.; Kirner, H. J.; Winnewisser, C. Adv. Mater. 2008, 20, 2217-2224.

7. Li, W.; Han, Y.; Li, B.; Liu, C.; Bo, Z. J. Polym. Sci. Part A: Polym. Chem. 2008, 46, 4556-4563.

8. Gaudiana, R.; Brabec, C. Nat. Photon. 2008, 2, 287-289.

9. Verified by NREL (see on www.konarka.com, press release of $12.09 / 2008$ ), to be published.

10. Dhanabalan, A.; van Duren, J. K. J.; van Hal, P. A.; van Dongen, L. J.; Janssen, R. A. J. Adv. Funct. Mater. 2001, 11, 255-262.

11. Jayakannan, M.; van Hal, P. A.; Janssen, R. A. J. J. Polym. Sci. Part A: Polym. Chem. 2002, 40, 251-261.

12. Kim, Y. G.; Walker, J.; Samuelson, L. A.; Kumar, J. Nano Letters 2003, 3, 523-525.

13. Jin, S. H.; Hwang, C. K.; Gal, Y. S.; Park, D. K.; Cho, S. J.; Shin, D. M.; Lee, J. E. European Polymer Journal 2004, 40, 1975-1980.

14. Naidu, B. V. K.; Park, J. S.; Park, S. M.; Lee, E. J.; Yoon, K. J.; Kim, S. C.; Lee, S. J.; Lee, J. W.; Gal, Y. S.; Jin, S. H. Sol. Energy Mater. Sol. Cells 2008, 92, 397-401.

15. Zhang, S.; Cyr, P. W.; McDonald, S. A.; Konstantatos, G.; Sargent, E. H. Appl. Phys. Lett. 2005, 87, 233101-233103.

16. Guo, Y.; Li, Y.; Xu, J.; Liu, X.; Xu, J.; Lv, J.; Huang, C.; Zhu, M.; Cui, S.; Jiang, L.; Liu, H.; Wang, S. J. Phys. Chem. C 2008, 112, 8223-8228.

17. Lin, Y. Y.; Lee, Y. Y.; Chang, L.; Wu, J. J.; Chen, C. W. Appl. Phys. Lett. 2009, 94, 063308-063310.

18. Huynh, W. U.; Dittmer, J. J.; Alivisatos, A. P. Science 2002, 295, 2425-2427.

19. Kang, Y.; Park, N.; Kim, D. Appl. Phys. Lett. 2005, 86, 113101113103.

20. Sun, B. Q.; Snaith, H. J.; Dhoot, A. S.; Westenhoff, S.; Greenham, 
N. C. J. Appl. Phys. 2005, 97, 014914.

21. Chang, C. H.; Huang, T. K.; Lin, Y. T.; Lin, Y. Y.; Chen, C. W.; Chu, T. H.; Su, W. F. J. Mater. Chem. 2008, 18, 2201-2207.

22. Sun, Y.; Yin, Y.; Mayers, B. T.; Herricks, T.; Xia, Y. Chem. Mater. 2002, 14, 4736-4745.

23. Chittibabu, K. G.; Balasubramanian, S.; Kim, W. H.; Cholli, A. L.; Kumar, J.; Tripathy, K. J. Macromol. Sci. Pure Appl. Chem. A 1996, 33, 1283-1300.

24. Neuteboom, E. E.; Meskers, S. C. J.; Van Hal, P. A.; Van Duren, J.
K. J.; Meijer, E. W.; Janssen, J.; Dupin, H.; Pourtois, G.; Cornil, J.; Lazzaroni, R.; Bredas, J. L.; Beljonne, D. J. Am. Chem. Soc. 2003, 125, 8625-8638.

25. Lee, K.; Kim, J. Y.; Park, S. H.; Kim, S. H.; Cho, S.; Heeger, A. J. Adv. Mater. 2007, 19, 2445-2449.

26. Hayakawa, A.; Yoshikawa, O.; Fujieda, T.; Uehara, K.; Yoshikawa, S. Appl. Phys. Lett. 2007, 90, 163517-163519.

27. Varghese, O. K.; Grimes, C. A. Sol. Energy Mater. Sol. Cells 2008, 92, 374-384. 